\title{
The Flip Side of Justice: The Two-Faced Spirit of The Dark Knight
}

\author{
Daniel Boscaljon
}

Time Magazine’s Richard Corliss, reviewing The Dark Knight, wrote that “[director Christopher] Nolan has a more subversive agenda. He wants viewers to stick their hands down the rat hole of evil and see if they get bitten.” Corliss's focus on evil makes sense given both the variety of villains populating the movie and the depth of Heath Ledger's Academy Award winning depiction of The Joker. I contend, however, that buried within the varied villains of the movie is a rare and precious vision of the good. It is in moving past the battle between Batman and Joker to focus on Harvey Dent that one finds a more complex vision of the good than what the two dominant figures embody. Focusing on Two-Face, the villain who provides hope, allows viewers to escape the pain of the "rat hole of evil."

Arguing how Harvey Dent emerges as the central figure of the film, and how both Batman and The Joker promote ultimately untenable visions of the good requires an in-depth analysis of evil and villains. I begin by building on Umberto Eco's 1972 essay “The Myth of Superman,” which I update by articulating why the figure of Batman has become increasingly important in the twenty-first century, replacing Superman as a focal point in our culture. I then analyze how Nolan depicts evil in the movie, focused on three kinds of villains: mobsters, The Joker and Two-Face. In order to make sense of the variety of villains, I turn to Immanuel Kant's conception of evil as a way of understanding the importance of The 
Joker, and then review Paul Ricoeur's conception of fallibility in order to make a case for Harvey Dent as the heart of the film. It is by emphasizing Dent's character that the movie makes its grandest moral statement, undermining the heterodirected nature of superhero logic that permeates other films and graphic novels in order to present the human capacity for autonomy and freedom.

\section{Heterodirection and the Myth of Superman}

Scholars throughout the humanities find that our worldviews are both undergirded and reinforced by the cultural artifacts that we unthinkingly consume: although we seek out meaningless diversions as a way to relax after a tiring week, the products provided for us are not offered with neutral intentions. What the Frankfurt School critics understood in terms of culture industry still holds true: at root, we as consumers remain a means to an end and not ends in ourselves. Cultural products always leave a residue that continues to frame and influence consumers long after the product itself has disappeared.

Umberto Eco's essay "The Myth of Superman” acknowledges the power that something as seemingly trivial as comic books has over its readers. This essay is particularly important as, thirty years after it was written, superheroes have transitioned from a niche market to become a dominant part of the entertainment industry. The seemingly inexhaustible stream of superhero movies, sequels and remakes, combined with the marketing tie-ins including action figures, clothing, costumes and posters represent a substantial portion of Hollywood's income. This was true in the 1980s, when Warner Brothers capitalized on the merchandizing success of Tim Burton's Batman, ${ }^{1}$ and is still true in the twenty-first century as The Avengers and The Dark Knight Rises break records for ticket sales.

Although Eco elucidates the ethical implications of superheroes based on the example of Superman as a primarily print-based phenomenon, his conclusions are applicable to filmed representations of Batman. Throughout his essay, Eco argues that the Superman comics helped to perpetuate a binary system of good and evil that hinged on property, such that "good" emerges from the protection of middle class property rights and "evil" is reduced to elements of theft (22). Instead of using his superpowers to end world hunger, eliminate dictators, stop wars or end poverty, Superman battles human and alien villains who attempt to seize property. These stories are offered in an iterative structure, which gives the illusion of a timeless world by preventing Superman from making decisions with serious implications (which would cause him to age) (16). Most comicsespecially in the 70s — were offered as a series of unrelated episodes, generating a 
non-linear temporal framework and hazy sense of the "present" that violates traditional notions of cause and effect (17). Eco claims that this combination of Superman's ethics and the episodic quality of each adventure reinforces a consumer mentality that values property and disregards the need for long-term calculations.

Eco uses the term "heterodirected" to talk about the social order produced by ideologies that reduce "good" to the possession and protection of property (without questioning its origin or necessity) and de-emphasize causal structures. Eco writes that,

In advertising, as in propaganda, and in the area of human relations, the absence of the dimension of "planning" is essential to establishing a paternalistic pedagogy, which requires the hidden persuasion that the subject is not responsible for his past, nor master of his future, nor even subject to the laws of planning according to the three ecstasies of temporality. All of this would imply pain and labor, while society is capable of offering to the hetero-directed man the results of projects already accomplished. Such are they as to respond to man's desires, which themselves have been induced in man in order to make him recognize that what he is offered is precisely what he would have planned. (19)

Marketing strategies realize Eco's contention that "Superman is no other than one of the pedagogic instruments of this society," and, further, that "the destruction of time that it pursues is part of a plan to make obsolete the idea of planning and of personal responsibility" (19). Readers are relieved of emulating Superman's responsibility because he is held to a higher standard and also because the temporality of his stories reify our forgetfulness about consequences beyond the moment.

Heterodirectedness, a condition that arises when we become directed by others in receiving and accepting culturally imposed norms and values as our own, thus emerges in the forfeiture of our own responsibility. Assuming that autonomy (or self-directedness) is an exceptional trait, we no longer worry about why we value what we do. Instead of seeking to create what we desire, we allow ourselves to be satisfied by products that we can own and consume. In so doing, we accept an entire framework of values in which justice, good and evil are reduced to questions of pleasure and property. Unthinking-heterodirected-we do not worry about the consequences about the future and accept the pleasure of being distracted by the moment. Eco's sense of heterodirection thus identifies and condemns 
our own passivity in the process of relinquishing our own freedoms to think, choose and create.

While one might hope that this paranoid logic might spring from Eco's characters in Foucault's Pendulum or The Prague Cemetery, the point instead seems to be borne out in the thirty years since the article was originally published. Arguing that the "hunger for entertaining narrative based on [iterative] mechanisms is a hunger for redundance" (21), a phenomenon witnessed not only in the proliferation of superhero movies and sequels but also in the short lifespan between their duplication, Eco shows how we are trained to consume cultural products because they are familiar. The hunger for redundancies and a heterodirectivity that encourages us away from critical thinking, combined with an ethics of charity and a civic consciousness stripped of greater political duties (22) lead to a passive world in which the $1 \%$ becomes wealthier and the $99 \%$ see themselves victimized again and again. Even though superheroes might appear to fight for everyone equally, saving the Earth (or at least a major city) from cataclysmic invaders who would destroy everything, Eco reveals how not everyone profits from the superhero's sacrifices beyond the world of the story.

\section{The Increasing Importance of Batman as Icon}

In the early 1970s, Superman was "the most popular of the heroes," and thus the proper target for analysis as "the one who is most carefully sketched, endowed with a recognizable personality ... the representative of all” (22). Even at that time, Eco acknowledged that other heroes (including Batman and Robin, next on his list) also uphold a small civic consciousness (attended by a lack of global political awareness) and ethic of charity (opposed to the evil that threatens private property) that ameliorate a consumer's heterodirection (21). Eco's analysis of "superheroes" in general, however, fails to keep certain differences in mind. Although most of the heroes he lists-including Flash, Green Lantern, the Fantastic Four and Spider-Man - are "gifted with such powers" that would allow them to "Take over the government, defeat the army, or alter the equilibrium of planetary politics” (22), Batman (and the Green Arrow, also listed) has no special power beyond training in martial arts, access to seemingly unlimited money, and the technology that money provides. What Eco misses is that unlike Superman or Aquaman, granting as super a "power" from money and technology normalizes it: unlike Thor or The Hulk, Batman's superior resources seem like an acceptable part of everyday life.

This distinction is married to a second that Eco overlooks: while Superman's 
universe is "divided into zones of Manichean incontrovertibility-where each authority is fundamentally pure and good, and each wicked man is rotten to the core without hope of redemption” (22), Batman's world is not as simple. Despite cooperation from the police force- especially James Gordon-Batman operates in ways that Law cannot sanction. Put otherwise, Superman-who fights for Truth, Justice and the American Way — does the good that police would do if they were "practically omnipotent ... in [their] physical, mental, and technological capacities," while Batman provides justice the Law cannot acknowledge. While Superman's quest to protect property is in line with the power structures, Batman's unauthorized attempts to uphold law undermine the superficially seamless relationship between government and force. ${ }^{2}$

These distinctions - a lack of super power and a more vexed moral framework - have helped allow Batman's less-than-super superhero to dominate popular culture. When Eco was writing in 1972, Batman's fortunes had recently taken a turn for the worse: after two years and 120 episodes of stylized, campy brilliance (Pow! Zing!), the television show (which ran from January 1966 to March 1968) was brought to an end by "a time dominated by the dark mood of Vietnam" where "Batman's slick jokiness began to wear thin" (Finkelstein and Macfarlane). Twenty years later, Frank Miller created a darker vision of Batman in 1986: both Batman: Year One and The Dark Knight Returns depicted a character who was, in Miller's words, "the mean one. The cruel one. The one who couldn't fly or bend steel in his bare hands. The one who scared the crap out of everybody and laughed at all the rest of us for being the envious cowards we were” (7). This darker Batman created the foundation for Tim Burton's 1989 surprise hit Batman: The Movie, which exceeded Time Warner's expectations by breaking several box office records, "including best Friday, Saturday, Sunday and weekend grosses, and emerged as the second highest domestic grossing film of all time by the end of its theatrical run” (Owczarski 117). This manifestation of Batman was infamously reduced to camp, exhausting itself in 1997's notoriously nipplesuited Batman and Robin, directed by Joel Schumacher in a misguided attempt to forget the lessons of the 1960s.

The third iteration of Batman-Christopher Nolan's 2005 Batman Beginsput Batman squarely at the forefront of popular culture once again. Dominating over 2006's forgettable Superman Returns, Nolan's vision for a Batman that wrestles with fundamental questions concerning the nature of justice and social good was eagerly consumed by a public who had learned to desire protagonists whose quests for justice were mired in ambiguity. The movie premiered in the midst of the triumph of the antihero on television, as Jack Bauer (24, 2001-2010) and Vic Mackey (The Shield, 2002-2008) had allowed for the line between law 
enforcement, criminal and vigilante to blur with unprecedented levels of violence. These protagonists fit with other antiheroes presented in The Wire (20022008), Deadwood (2004-2006) and The Sopranos (1999-2007), all of which appealed to a postmodern culture too suspicious to accept the bravado of "Mission Accomplished" as more than empty rhetoric. In a century born in the ashes of tragedy and two wars of dubious necessity, it is unsurprising that cultural icons would exist in a world where justice, force and law were increasingly divergent. As Manohla Dargis put it in The New York Times, “Apparently, truth, justice and the American way don't cut it anymore. ... it helps get at why, like other recent ambiguous American heroes, both supermen and super-spies, the new Batman soared."

In addition to his lack of a superpower and his tension with authority, Batman differs from Superman in one final way that is advantageous for his current cultural relevance. Eco argues that the "mythological character of comic strips" requires that a character "be an archetype, the totality of certain collective aspirations," which means that he must simultaneously be "easily recognizable" and "subjected to a development which is typical ... of novelistic characters" (15). Superman allows one specific way to bridge the typical and the heroic, making identification with the superhero possible and desirable. Eco writes,

Clark Kent personifies fairly typically the average reader who is harassed by complexes and despised by his fellow men; through an obvious process of self-identification, any accountant in any American city secretly feeds the hope that one day, from the slough of his actual personality, a superman can spring forth who is capable of redeeming years of mediocre existence. (15)

Clark Kent embodies the mediocrity that we fear dwells at the heart of us all, and Superman figures wish fulfillment at two levels: the person we think we should be (the ideal ego) and the powers we wish we had (the ego ideal). Eco's argument that the combination of these three factors is the recipe for the perfect hero in the 1970s is not surprising.

The figure of the Batman, as reconceived by Miller and developed to its logical extreme by Nolan, is more complex in what it offers and requires by way of identification. The logic of the secret identity is reversed in this figure: if Kent is the unglamorous mask behind which the noble Superman hides, then Bruce Wayne is the libertine underneath that the ignoble Batman tolerates. Nolan's combination allows the viewer to dream of the possibility of a justifiable libidinal 
excess, in which violence, sexuality and conspicuous consumption merge in a potent blend of forbidden and impossible desires. Rather than a Clark Kent, open to the $99 \%$, Bruce Wayne represents the member of the $1 \%$ that everyone can wish to be. Wayne's wealth is wisely treated as a burden and spent with an ironic extravagance that allows us to enjoy the lavish lifestyle without feeling guilty for desiring it: in other words, we find his excesses acceptable because they are intentionally frivolous. All too often, this is a behavior that we give ourselves permission to emulate.

Discarding the disposable dorkiness of clumsy Kent, Nolan's protagonist fuses id and superego, which presents an ideal of wholeness and integration that in many ways is as attractive as the lavish lifestyle and powerful physique. Rather than relating to an anonymous exterior that provides access to a framework of moral certainty, we can identify with Nolan's Batman only after we confront and confess the ambivalence about our desires and our uncertainties about the nature of power and justice. Clark Kent's insecurities are merely feigned, or exist relative only to human relationships: Bruce Wayne/Batman's insecurities are very real, and it is through accepting them that the promise of integration is born. In a world where declarations of certainty, like declarations of an "Axis of Evil," ring hollow, it is not surprising that integration would be deemed a higher kind of good than moral certainties that lead to error. Batman is a different kind of heroa "Dark Knight" - but Nolan's use of a hero whose appeal rests on morally dubious libidinal expressions requires that we distinguish the hero from the villain. In order to understand what "good" means, in other words, it is necessary to analyze the ways that Nolan's villains characterize evil.

\section{"Evil" in the Dark Knight: the Villain who desires social order}

Plato's Republic offers a vision of the city as a model of the self: writ large, Socrates argues that we can see the nature of a justice that also lies within the hearts of individuals. This justice is an integrated balance of parts in relation to a whole toward which these parts contribute. Socrates argues that in the same way that a just city is ruled by a philosopher king, defended by guardians and served by a merchant class, so also does a just individual use reason to rule over the appetites, served by a spirit whose allegiance generally serves the interests of reason, but occasionally will serve as a check against rational detachment. The city Socrates envisions has nothing to do with Nolan's Gotham: in Batman Begins, the city is depicted as physically deteriorating from the inside out. The Dark Knight (also based in Chicago) reveals a city whose deterioration is internal: 
government officials are assassinated or hide, as corruption lurks deep within the hearts of those entrusted to protect the city. No matter which scale one uses, justice is difficult to encounter.

Nolan offers a glimpse of a diseased Gotham in The Dark Knight; mediated by IMAX cameras for a fuller image, the viewer is introduced to seven different kinds of villain in the first ten minutes of the movie:

1) Dopey, Happy, Grumpy, Chuckles: a gang of clowns who help rob a bank before being executed.

2) Bozo (The Joker): the leader of the heist.

3) The Bank Manager (William Fitchner): responsible for laundering and protecting the mob's earnings.

4) A drug dealer.

5) Detectives Ramirez and Wuertz: cops whom the viewer learns later are corrupt.

6) The Scarecrow: the super villain from Batman Begins, reduced here to a drug supplier.

7) Organized Crime (represented by the Chechen man purchasing drugs from the Scarecrow).

The interest of the movie is clarified within the first ten minutes. The gang of clowns that the Joker hires does not escape from the bank alive; the bank manager fails to protect the mob's money and knows that he is as good as dead. Batman's influence on the drug dealer (in a scene that mirrors the introduction of Burton's Batman) is noted, and Nolan's Batman quickly dispenses with the Scarecrow and the Chechen's thugs. The type of villain that the Joker represents is identified by the morally (and financially) bankrupt bank manager, who tells "Bozo" (The Joker) that "Criminals in this town used to believe in things ... Honor. Respect.” Before the manager can finish asking "What do you believe?”, The Joker has placed a grenade in his mouth. Nonetheless, The Joker answers the unfinished question as he pulls off his clown mask to reveal his scarred mouth and the unsettling makeup underneath the mask. Speaking with speech marred by a soft, sucking lisp: "I believe that what doesn't kill you ... simply makes you stranger."

Nolan uses this initial conversation to contrast the evil represented by the Joker with that displayed by the other characters. Although the bank manager is aware that he is working for the mob, he nonetheless argues that these criminals have a belief in social order that transcends the instances in which they break it. Put otherwise, the mob-like the drug dealers, the corrupt cops, the gang of clowns and 
the Scarecrow-desire justice as a universal rule, and see themselves only as occasional and particular exceptions to this universal norm. This form of evilthat which Eco identified as the main ethical conflict within superhero comicsreveals its tendencies toward a just society, and the order that this society desires. Plato might diagnose this as an imbalance of the appetites, an inconsistency that acknowledges the need for a just society. The importance of Nolan's characterization of this kind of villain as one who desires the good means that beyond teaching that crime does not pay, the traditional superhero villain also implicitly nods to the good of social order and control.

\section{Absolute Evil in the Dark Knight: The Joker}

If Corliss is correct, and The Dark Knight constitutes a superhero movie that interrupts the system of heterodirection that Eco correctly criticizes, the seeming point of distinction rests in Heath Ledger's portrayal of the Joker. Manohla Dargis writes that "Mr. Nolan has turned Batman into a villain's sidekick. That would be the Joker, of course, a demonic creation and three-ring circus of one wholly inhabited by Heath Ledger." In the production notes, Nolan states that he wanted to create a villain who "is still coming from a place of reality," and so "began with the notion of The Joker as the most extreme form of anarchist-a force of chaos, a purposeless criminal who is not out for anything and so, can't be understood" (4); later, Nolan adds that "We wanted The Joker to represent pure, unadulterated evil, in the sense that he has no logical motivation for his actions. That is what we wanted to unleash on the city of Gotham. He is an absolute” (8). This adheres with the Platonic notion of good and evil discussed above: good correlates with the harmonious balance of the rational, evil with what is chaotic.

In his analysis of the film, Charles Bellinger takes up the proposition that The Joker can be seen as a Satanic figure, using Girard's analysis of mimetic desire. Building on Girard's insight that "Satan is the seducer who alienates people from God and insinuates to them that they must long for something that they supposedly lack," Bellinger argues that The Joker is like Satan, in that both "“[kick] it up a notch' into rivalry, conflict, and chaotic violence" (6). Arguing that the Joker realizes that "Batman is actually his ally in the satanic event" (10), Bellinger hints toward what the audience experiences as evil-the undoing of that which does good. In his most interesting point, Bellinger argues that the Satanic work of the Joker is to expose as evil the heterodirectivity in place within society-in short, Bellinger finds that Satan is the force of mimetic desire that directs the heterodirected. He writes, 


\begin{abstract}
Satan is at work in the actions of the criminal, but when the criminal is apprehended, tried, and retributively punished, society is acting as a lynch mob that is also secretly inspired by Satan. When this is seen, the rhetoric of "Justice" becomes empty, or worse than empty, it becomes the evil of hypocrisy. This is why I say that the filmmakers may have put into The Joker's mouth a line that is more profound than they realize. To understand that Satan is a shapeshifter who can be in the criminal and in a defender of Justice, such as Harvey Dent or Batman, is to deconstruct the (good guys vs. bad guys) genre of the film. In contemporary political parlance, if the bad guys, the evildoers, and those who are carrying out the War on Evildoing are all fulfilling Satan's agenda without realizing it, then the world is utterly dark. (11)
\end{abstract}

Bellinger does not end on such a bleak note, and instead attempts to recover Batman as a Christic character willing to serve as a scapegoat-consistent, of course, with his Girardian premise. The conclusion of Bellinger's essay, however, is unsatisfying - almost as though he merely wanted to offer the possibility of hope without being able to overcome what Nolan constructs as the possibility of perverse heterodirection. What Bellinger misses, in his abrupt and uncompelling shift to Christic possibilities, is the fact that Nolan and Ledger's characterization of The Joker exposes the logic of heterodirection instead of replicating it: by explicitly mocking as petty the desire for property, The Joker seemingly represents a way out.

Most movies allow audiences to feel good when a hero triumphs over eviland thereby perversely reinforce the simplistic ethic underlying the heterodirected worldview Eco describes. Although Nolan's movie risks a blatant dismissal of heterodirected values and mimetic desires and ends with an injustice and a lie, this ending is intended to highlight the tragic consequences of The Joker's logic, making it more likely that the audience rejects this worldview and leave the theater without reconsidering the desire to consume. Thus, although The Joker is portrayed in line with a Nietzschean superman, someone beyond good and evil, the movie as a whole frames him less as an übermensch and more as a traditional superman. The end of the film teaches that embracing chaos leads to injustice and tragedy, allowing the audience to dismiss The Joker's insights without fully contemplating, considering or internalizing them.

Pausing for a moment, however, it is possible to take The Joker as an end in himself-dismissing, momentarily, the implication of the film's conclusion- 
examining the extent to which humans are capable of absolute evil. In his Religion Within the Boundaries of Reason Alone, Immanuel Kant examines the question of human nature. Distinguishing between doing something evil and being evil, Kant argues that at most an evil action would allow others to infer the presence of an evil maxim. Holding that evil is a result of choice, and a "naturally" evil person would be denied the freedom that evil requires (46), Kant's argues that the root of evil is in freedom, and that this freedom is invariably exercised with regard to the moral law — even if this means ignoring the moral law instead of upholding it (50). After this prologue, Kant addresses the origin of our predispositions toward good and evil. He argues that humans are predisposed toward the goods of living, rationality and responsibility (50), but warns that these goods encourage vices that arise from an abundance of self-affection. Thus, the good of living includes a desire for self-preservation, but can encourage "bestial vices" of gluttony, lust and wild lawlessness. While rationality allows us an understanding of worth, this impulse can become vicious when we desire superiority instead of equality. Referring to these as vices of culture, Kant argues that they become diabolical with an extreme degree of malignancy-including a joy when others suffer (51). Finally, at the level of personality, Kant concludes that our ability to respect the moral law and determine that its influence provides a sufficient incentive to power allows reason to legislate unconditionally (52).

Kant uses the platform of his description of the good to provide an analysis of evil. He argues that humans are susceptible to three grades of evil: frailty (the weakness of the human heart), impurity (or the adulteration of moral incentives with immoral ones) and depravity (the propensity to adopt evil maxims). All humans are troubled by frailty, such that we are able to determine the good of the moral law objectively_-but find it less compelling relative to our own interests. Impurity erodes our potential for good when, confronted with the absolute nature of the moral law, we attempt to add incentives toward it in order to supplement our own desires, but thereby pollute its absolute nature (53). Finally, Kant argues that depravity emerges as the supplement supplants the moral law, becoming more important than it and reversing the ethical order (54). This propensity toward evil, the more attractive interest of our own self-love above the summoning of the moral law, is radical in nature, and Kant reasons that it corrupts the ground of morality in general.

Kant's analysis provides a backdrop against which the nature of The Joker's evil as absolute can be measured: in short, The Joker manifests evil on all levels. Relative to goods, The Joker's viciousness reaches levels of wild lawlessness that continually threaten to undermine even the good of his own self-preservation. Clearly, he experiences the desire for superiority and experiences a joy at the 
suffering of others. Acting relative to the moral law, The Joker clearly indicates a preference for its negation, living a life of almost impossibly perfect depravityresulting in his decision to push others into lives of evil, preying on the frail hearts of others and exposing the capacity for humans to choose self-interest over what is morally good.

Against this framework, Bruce Wayne and Batman seem to fare better: Bale consistently portrays Batman as sacrificing the goods indicated by a self-love in order to secure the ability for others to maintain their freedom as rational actors. This includes sacrificing the good of self-preservation (risking his life and the chance for offspring) and sacrificing a relationship that he desires (with Rachel Dawes). Although Batman's willingness to transgress human law (engaging in violence, kidnapping, surveillance) might indicate an abrogation of the moral law, Batman does so as a way of ultimately securing law_-specifically, as his work against the mobsters signifies, law upholding property rights.

The Joker's disdain for the good of his own well-being extends also to an animosity toward private property. Rather than the rational re-appropriation of private property to serve his own needs (which we more commonly describe as "theft"), The Joker finds that property is only important for sending a message. As he burns a thirty-foot tall stack of bills, the Joker criticizes the Chechen gangster, saying, "All you care about is money. This city deserves a better class of criminal." He clarifies what he means by "better" in terms that mock a belief that money or property is an end in itself: "It's not about money, it's about sending a message. Everything burns." Professing to be "a man of simple tastes" who desires "Dynamite ... gasoline," The Joker desires that which promotes the destruction of life instead of its perpetuation in a manifestation of the will to power.

Beyond his willingness to stake his own life on other people's tendencies toward the moral good that he seeks to undermine, The Joker's evil is also disturbing in its pervasive nature. He consistently turns people against each other using greed (the gang of clowns) or threat of force (the mobsters, people on the boats). Even when he is thwarted in his attempts at corruption, The Joker constructs situations that require others to test the extent to which they will sacrifice their own interests for the moral law. This is most concretely framed by forcing Batman to choose between saving Harvey Dent-the District Attorney who represents Gotham's best chance at wholeness within the confines of law-and Rachel Dawes - the woman he has spent a lifetime loving. Unlike the similar scene in Schumacher's Batman Forever, in which the Riddler forces Batman to choose between his partner and a woman he finds attractive, Nolan's Joker forces Batman to choose between the good suggested by the moral law (saving the life of a man whom he admires but does not like) and that suggested by his heart (a wom- 
an with whom he has a long-standing relationship). The fact that the Joker deceives Batman about the nature of this choice is an added element of evilrubbing insult into Batman's injury.

The third way that Nolan and Ledger construct a figure of absolute evil is through the Joker's work of showing the fallibility of reason itself, exposing its shortcomings and diminishing its possibilities. In Kantian terms, The Joker's attempts to push people to confront the specter of irrationality that undergirds decisions undermines the identity of reason and justice, and casts a shadow on the definition of the good promoted by Plato and Kant. The maxim that he seems to follow is what he tells Batman when in interrogation: "The only sensible way to live in this world is without rules.” Throughout, The Joker delights in revealing what Kierkegaard (and Derrida after him) posits as the moment of insanity at the heart of every decision, showing the folly at the heart of feeling that the future is certain. In speaking to Harvey Dent, The Joker articulates his ethos in terms of scheming, telling Dent, "Schemers trying to control their worlds. I'm not a schemer, I show the schemers how pathetic their attempts to control things really are." Rather than denying the ability for reason to make predictions about the future predicated on causality, The Joker's efforts instead focus on undermining the "pure" foundation of reason, showing the hypocrisy of what is assumed in a heterodirected world. "Nobody panics when the expected people get killed. Nobody panics when things go according to plan, even if the plan is horrifying ... Introduce a little anarchy, you upset the established order and everything becomes chaos. I'm an agent of chaos. And you know the thing about chaos, Harvey? It's fair." Although chaos and fairness both require some amount of disinterestedness, The Joker's formulation removes justice from the heart of reason and puts it, instead, at the heart of irrationality. Rationally speaking, after all, the interest of justice is always the good.

Becoming a spokesman for what is fair-not for what is legal or what is "just," The Joker seems to undermine his own status as a villain-much less as a supervillain. Not only does The Joker indict our complicit attitudes toward injustices that continue due to our own heterodirected natures, and thereby exceed the "heroes" who are skewered by Eco's critique, but The Joker also exposes the limitations of Kant's definition of Absolute Evil—which exists, sadly, on the basis of evil alone. After all, absent any sort of maxim of self-love, The Joker as a self-directed agent of chaos seems to exist beyond good and evil-in a way that indicts our desire to cling toward a sense of right and wrong. To this extent, The Joker could do no better than burn a pile of money: the message that "everything burns" serves to warn the viewer about the dangers of a heterodirected lifestyle that assumes that money is an end to itself-or even, possibly, the means to a 
beneficial end. This message, especially when viewed after the Occupation movements of 2011 (which also drew attention to the financial injustices perpetuated by the legal structure), seems to excuse some of The Joker's more villainous excesses.

Additionally, The Joker does not personally cause the majority of the violence blamed on him - in fact, the function of The Joker seems less to cause harm than to expose fault lines in human society. This is the excuse that he provides Dent, reminding him that he "was sitting in Gordon's cage” and "didn’t rig those charges" when Dent and Dawes were kidnapped. Rather than act, The Joker involves himself in creating situations that test the mettle of the individuals at hand, questioning "how loyal a hungry dog is" when telling the Chechen that he is taking over the city. In setting up a hostage situation in which passengers on two boats must either detonate explosives on the other boat or risk having both boats explode, The Joker desires to allow everyone to "learn a little bit about ourselves." While he might bribe or tempt others to violate the law, The Joker seems most interested in providing situations that test the integrity of characters - and, mimetically, the audience. These situations — often put in terms of "kill or be killed" are impossible to navigate with an ethics predicated on reason, and thus expose the irrelevance of reason at their heart. While there are clearly exceptions, The Joker primarily creates opportunities to engage in evil instead of doing evil himself. ${ }^{3}$

Interestingly, Elaine Pagels argues that the adversarial position where one tests another is the original function of the Satan, a term translated as "the accuser" in Biblical Hebrew. In her book The Origin of Satan, Pagels examines different texts in which the Satan is employed, and finds that its initial form is to test the quality of a person-Adam, Eve, Job, and perhaps Jesus. While The Joker occasionally uses direct violence to harm another, he more frequently designs scenarios that expose the tenuous nature of most people's morality. He mocks Batman with this fact, stating "Their morals, their code ... it's a bad joke. Dropped at the first sign of trouble. They're only as good as the world allows them to be. You'll see-I'll show you ... when the chips are down, these civilized people ... they'll eat each other. See, I'm not a monster ... I'm just ahead of the curve.” Like Kant, The Joker recognizes that most people supplement their moral code with various forms of self-affection, and that their embrace of moral norms is conventional at best. The Joker selects his targets carefully-Coleman Reese, for example, has his life staked against a hospital only after he threatens to expose Batman, which causes The Joker to reflect, "Of course, you could always kill yourself, Mr. Reese. But that would be the noble thing to do. And you're a lawyer.” Here again, The Joker points to the way that self-affection impinges upon the moral law, 
causing us to find that our own self-preservation is better than the good of the lives of others.

The Joker's main targets throughout the movie, however, are those who deem themselves capable of executing the law-Mayors, Judges, Commissioners, Lieutenants, Attorneys, vigilantes. The primary targets are Gordon, Dent and Batman - the three who set themselves up as having integrity beyond what the law requires. In Dent's words, they were three men who "thought [they] could be decent men in an indecent world," who "thought [they] could lead by example," that "the rules could be bent but not break." Although the Joker is interested in what happens to the city when "their spirit breaks completely," he also understands that the nature of the test depends on the strength of the best in the city. In a final scene that parallels Burton's Batman and Joker climax, The Joker judges Batman as "incorruptible" but finds that Dent is fallible, claiming "I brought him down to my level," a level at which a desire for personal goods corrupts the ability to cling to the moral law. Dent is judged, and is found lacking.

Rescuing The Joker from the possibility of this type of helpful satanic activity, however, Nolan ensures that the viewer suspects the Joker's assessment of Batman, especially given the way that The Joker's opinion changes throughout the course of the movie. Although he is initially intent on having Batman expose himself, killing "fake" Batmen to draw Batman out of hiding, he ends up realizing that a world without Batman, filled with the heterodirected activity of theft and imprisonment, is "boring." During his interrogation, The Joker tells Batman as much: "Kill you? I don't want to kill you. What would I do without you? Go back to ripping off Mob dealers? No you ... You. Complete. Me.” Unlike Dent and Gordon, who support the law within the boundaries created by the law, The Joker comes to relish Batman's desire to support a heterodirected system that protects private property and his willingness to go to illegal extremes in order to uphold the law. Undermining the Joker's ability to render a good judgment absolves Dent from The Joker's accusation.

Although The Joker never learns Batman's other identity-Bruce Wayne-in the screenplay, one can picture his laugh were he to find out. The joke, in this case, would be on Gotham: the billionaire supports a system of inequality, securing government funding to augment his desire for technology that allows him to feel above the law. This is the only distinction that Batman is able to put between himself and the "fake Batman" who asks "What's the difference between you and me" at the beginning of the movie: Batman answers "I'm not wearing hockey pads" before driving away in a Batmobile originally invented for the military. Using his fortune to fund a private war and extravagances that keep his identity secret make Batman a hero that is difficult to idealize. Ultimately, and perhaps 
unsurprisingly, Nolan creates a Bruce Wayne who, as a member of the $1 \%$, is willing to violate the law to ensure that he remains part of the $1 \%$. More than anyone else, Bruce Wayne is the one least able to afford an agent of chaos who would disrupt the flow of capital, or expose the fact that money, like everything else, burns. In seeming to absolve Batman, The Joker manages only to implicate him.

\section{Two-Face and Affective Fragility}

The Joker pushes the audience toward a suspicion of a rationality that equates justice and law without threatening the moral law that Kant asserts is at the heart of each of us. If guardians of Gotham's law play the role of the superego, and The Joker manifests the id-like chaos of unfettered, homodirected appetite, then the final main character of the movie represents thumos, spirit, the guardian of the city. Just as Gordon and Batman discuss having "bet it all” on Harvey Dent, so also does Nolan's film direct viewers interested in settling the question of Good and Evil (unsettled by The Joker) toward the figure of Dent.

In his book Fallible Man, Paul Ricoeur argues that the inner conflict felt by humans is caused by an internal disproportion which infects human knowing, acting and feeling: this, he says, "takes on the name of fragility in the affective order" (125), represented by the restless spirit that unsettles the heart (126). Arguing that "the fragility of the human being" puts "conflict" in our "most primordial constitution," Ricoeur argues that "external conflicts could not be interiorized if a latent conflict did not precede them." This conflict is one that struggles "between living and thinking, of which our 'heart' suffers the primordial dischord" (132). Ricoeur makes us aware of the space between life and thought, appetite and reason, id and superego, chaos and order, and points out that this space exists in spite of Plato's emphasis on the rationality of a philosopher king: disorder does have a place in our lives, a place that we need to integrate carefully. Clearly, Nolan is also aware of the tension between living and thinking - forcing choices between these is The Joker's specialty_and he presents this space at the core of human struggles, one that pushes us toward opposing decisions often fought out in the name of good. Building on Kant to argue that human ontology is predicated on a limitation equivalent to fragility (140), Ricoeur argues that our experiences of humans consist of the "becoming of an opposition: the opposition of originating affirmation and of existential difference" (141). Ricoeur calls the internal disproportion at the heart of feeling our "affective fragility" (106).

The main argument of Ricoeur's book is that evil emerges in our affective fra- 
gility, as spirit (thumos) fights in the unceasing conflict between the rival goods of thinking and living, pleasure and happiness. The possibility for evil arises "in an increasing order of complexity from the occasion to the origin and from the origin to the capacity" (141). Humans for Ricoeur remain fallible- - but not inherently corrupt. The thought of innocence becomes possible only in an "imaginary mode" through which one finds "fallibility without fault, and this fallibility would be only fragility, only weakness, but by no means downfall” (144). The flaw in the Joker's argument, and the true (and only) source of hope in the movie arises from his encouraging the activation of the human capacity for evil by providing occasion, and considering the presence of weakness as proof of guilt.

Although all of the characters agree that Harvey Dent is "lost" due to his unsanctioned acts of violence, one can read Two-Face as the true hero-not a villain. Instead of continuing to support a heterodirected system that protects property and encourages the rule of reason that is able only to pretend "disinterest," Dent and Two-Face both manifest spirit and a desire-as Aaron Eckhart puts it in the production notes - to pursue justice "outside of the law he once lived by" (11). Dent as Two-Face does not treat his code like a bad joke, but instead exposes the bad joke at the heart of institutionalized justice. His coin, defaced, is not a sign (like money) but embodies a disinterested justice that Two-Face immediately executes: metonymically, the property of the coin transfers to him. The flipping of the coin in a series of restless spins represents Dent's desire to see an impossible justice realized, a justice that emerges from the cry of spirit instead of the dictates of law. More than revenge, Two-Face's campaign to punish those who wronged him is a response to the call of justice felt at the level of passion, at the heart. The coin literalizes the fluctuation of the heart between two competing goods, performing the work of judgment that shows the sham at the heart of the courtroom. Far from broken, Dent realizes that "the only morality in a cruel world is chance. Unbiased. Unprejudiced. Fair.” The coin allows Dent to make decisions that satisfy his passion for fairness without violating reason or appetites. Like thumos, the spirit or heart that vacillates between the good of reason and the good of appetite, the two faces oscillate between the fairness of reason (law and hierarchy) and the fairness of chaos (chance and disinterest) impersonally. Two-Face is a villain only because society too scrupulously protects the secret pact between violence and reason as a way of keeping a monopoly.

In the heart of the heart of Gotham, Nolan shows how truth manifests as a chance that literalizes the restless struggle felt within us all. The uncompromising spirit of Harvey Dent could neither side with a system that supported a heterodirected system of law nor with a chaos that neglected and undermined all order. As the true face of justice within the movie, a face which exposes its own interiority 
without the need to wear a mask, both Dent and Two-Face provide a vision of the Good that escapes Eco's critique of heterodirection, a vision of fairness that satisfies our spirit, a depiction of justice that does not attempt to hide human limitation. While Schumacher had Tommy Lee Jones present a Two-Face as an incoherent impersonation of Jack Nicholson's Joker, Nolan's Two-Face is a villain only for those too scared or too ashamed to realize that true justice lies in the fragility of the heart.

\section{Evil in the Dark Knight}

David Denby's review of The Dark Knight in The New Yorker presented a unique reminder that the film's function is ultimately to make a profit, not to resolve questions of justice. He wrote, “'The Dark Knight' has been made in a time of terror, but it's not fighting terror; it's embracing and unleashing it-while making sure, with proper calculation, to set up the next installment of the corporate franchise.” The Batman movie franchise has long been identified as important from a business perspective, especially because Burton's first Batman had success that "reached beyond the box office records it broke. It also propelled other divisions of the company including its music, licensing, and publishing arms, as its soundtrack sold soundly and Batman products flew off shelves" (Owczarski 117). The wild successes of both Batman Begins and The Dark Knight reveal the skill with which the producers have been able to guide the storyline. What makes the movies special beyond commercial success-or perhaps one portion of what makes the product commercially potent-is the fact that it offers more than what one can easily consume, opening the door to force each viewer to judge for her or himself.

Nolan does not require much to allow people to reject The Joker's perspective as a viable way to resist heterodirection: by the end of the movie, The Joker's sublime character repels viewers as much as attracts them. More is required to show the faults in Batman, but these manifest when considering Bruce Wayne's vested interest in protecting the system of property: Batman's work in ensuring that justice remains relegated to the realm of law alone remains something that the movie refuses to comment upon. Although Bruce Wayne does not have omniscient powers, Eco would criticize him for ignoring what could more concretely be done to end injustice and poverty in addition to buying a Russian Ballet company and seaplane as a way of kidnapping a crooked accountant in Hong Kong.

The movie's true courage comes in revealing that the importance of Dent's 
quest for revenge equals his attempt to prosecute the Mob. This sentiment lingers after the death of Dent and unsettles the noble lie that makes Batman/Bruce Wayne "The Dark Knight." Within the world of the movie, the lie is that Batman was responsible for the murders that Dent committed: relative to the world of the viewers, however, the lie is that a simple ethics of property is adequate, that The Joker's Nietzschean depiction of a homodirected life is villainous, and that we must choose between a justice controlled by reason (that results in order) or appetite (that results in pain). This lie excludes as a choice the justice undertaken by spirit that would threaten the government's monopoly on power, one where individuals—not the government- take responsibility for social justice. Dent's "villainous" character thus disrupts the dichotomy between difficult goods and deplorable evils that The Dark Knight seems to offer, insisting on a third way between murky absolutes.

In other words, the genius of Nolan's movie rests in allowing an alternative to creep between The Joker's seductive excesses and Batman's flawed heroism, an alternative that persists past the film's stated conclusion. Including Harvey Dent as the thumos of the movie allows viewers to find a less-than-super human as a point of identification. Fallible and frustrated, Dent's desire to do good and preserve passion provides an example of autonomy that works against the heterodirected order of comic book logic without The Joker's absolute opposition. Perhaps most remarkably, instead of providing the viewer with a pre-digested determination of good and evil, Nolan allows each viewer to independently interpret whether Dent or Two-Face has the final say-whether the most human character is villain or hero. This judgment, made apart from heterodirected systems of consumption, potentially becomes the cornerstone of one's self-evaluation, of an autonomous ethical order. Although less widely discussed than The Joker or Batman, it is through Harvey Dent as "villain" that Nolan provides a subversive glimpse of a justice beyond property rights and a hint of a better kind of good.

\section{Notes}

${ }^{1}$ Kimberly Owczsarski writes, "As the success of Batman reached from the box office to video sales to hundreds of millions of dollars in merchandise sales, it became clear that the film would be a 'prototype' for other franchise films to follow, particularly with any Batman sequels" (119).

${ }^{2}$ Derrida argues that the fear of the state is not "not so much crime or robbery, even on the grand scale of the Mafia or heavy drug traffic, as long as they transgress the law with an eye toward particular benefits," but instead fears "founding violence - that is, violence able to justify, to legitimate, or transform the relations 
of law, and so to present itself as having a right to right and to law" (268). When police blur this line and legislate as they enforce, it causes a "revolting ambiguity" because this use of violence (preserving law) too closely resembles an "illegitimate" lawmaking violence. Because Batman pursues justice beyond the law with a violence that the law cannot sanction, his use of force undermines the order he would ostensibly uphold. It is worth noting that he protects his unique status as costumed vigilante, deterring those who would exercise unsanctioned force in a similar fashion.

${ }^{3}$ Guy Debord's criticism of the spectacle and his work on creating situations provides a theoretical lens capable of explaining The Joker's habit of prolonging the process before the explosion instead of dwelling upon the aftermath.

\section{Works Cited}

Bellinger, Charles K. "The Joker is Satan, and So Are We: Girard and The Dark Knight.” The Journal of Religion and Film 13.1 (2009): n. pag. Web. 20 Feb. 2012.

Corliss, Richard. "Batman Is Back—TIME Reviews The Dark Knight." Rev. of The Dark Knight, dir. Christopher Nolan. Time Magazine. Time, Inc. 09 July 2008. Web. 20 Feb. 2012.

Denby, David. "Past Shock: 'The Dark Knight' and 'WALL-E.”' Rev. of The Dark Knight, dir. Christopher Nolan. The New Yorker. Condé Nast. 21 July 2008. Web. 20 Feb. 2012.

Dargis, Manohla. “The Dark Knight (2008): Showdown in Gotham Town.” Rev. of The Dark Knight, dir. Christopher Nolan. The New York Times. The New York Times Co. 18 July 2008. Web. 20 Feb. 2012.

Derrida, Jacques. "Force of Law.” Jacques Derrida: Acts of Religion. Ed. Gil Anidjar. Trans. Mary Quaintance. New York: Routledge, 2002. 228-298. Print.

- The Gift of Death. Trans. David Willis. Chicago: University of Chicago Press, 1996. Print.

Debord, Guy. Comments on the Society of the Spectacle. New York: Verso, 2011. Print.

Eco, Umberto. “The Myth of Superman.” Diacritics 2.1. (1972): 14-22. Web. 20 Feb. 2012.

Finkelstein, David and Ross Macfarlane. "Batman’s big birthday.” The Guardian. Guardian News and Media Ltd. 14 March 1999. Web. 20 Feb. 2012.

Kant, Immanuel. Religion Within the Boundaries of Reason Alone. Trans. Allen Wood and George Di Giovanni. New York: Cambridge University Press, 2006. Print.

Miller, Frank. The Dark Knight Returns. New York: DC Comics, 1997. Print.

Nietzsche, Frederich. Beyond Good and Evil. Trans. Walter Kaufmann. New 
64 IJCS

York: Vintage Books, 1989. Print.

—. Thus Spake Zarathustra. Trans. R. J. Hollingdale. New York: Penguin Books, 1969. Print.

The Dark Knight. Dir. Christopher Nolan. Perf. Christian Bale, Heath Ledger, Michael Caine, Gary Oldman, Morgan Freeman. Warner Brothers, 2008. Film. Owczarski, Kimberly Ann. "Batman, Time Warner, and Franchise Filmmaking in the Conglomerate Era.” Diss. University of Texas Austin, 2008. Web. 20 Feb. 2012.

Pagels, Elaine. The Origin of Satan: How Christians Demonized Jews, Pagans, and Heretics. New York: Vintage Books, 1996. Print.

Plato. The Republic. Trans. Desmond Lee. New York: Penguin Classics, 2007.

Production notes. The Dark Knight. Dir. Christopher Nolan. Perf. Christian Bale, Heath Ledger, Michael Caine, Gary Oldman, Morgan Freeman. Warner Brothers, 2008. Web. 20 Feb. 2012.

Ricoeur, Paul. Fallible Man: Philosophy of the Will. Trans. Charles A. Kelbley. New York: Fordham University Press, 1986. Print. 